\title{
ROPIVACAINE VERSUS BUPIVACAINE-LIGNOCAINE MIXTURE IN PERIBULBAR BLOCK- A COMPARATIVE STUDY
}

\author{
Rahul Varshney1, Vimlesh Sharma², Urmila Palaria ${ }^{3}$, Anshika Kashyap ${ }^{4}$ \\ 1 Junior Resident, Department of Anaesthesiology, Government Medical College, Haldwani. \\ ${ }^{2}$ Assistant Professor, Department of Ophthalmology, Government Medical College, Haldwani. \\ 3 Professor, Department of Anaesthesiology, Government Medical College, Haldwani. \\ ${ }^{4}$ Junior Resident, Department of Ophthalmology, Government Medical College, Haldwani.
}

\begin{abstract}
BACKGROUND

Ropivacaine is a newer local anaesthetic agent with low systemic side effects. It has the potential advantage of reduced cardiovascular and neurological toxicity compared with other available local anaesthetics that are commonly used for peribulbar anaesthesia. In this study, we intend to compare the efficacy of Ropivacaine as against Bupivacaine-Lignocaine mixture in peribulbar anaesthesia.
\end{abstract}

\section{MATERIALS AND METHODS}

A prospective, randomised study was conducted on 100 patients undergoing elective cataract surgery by phacoemulsification under peribulbar block at Dr. Sushila Tiwari Memorial Hospital, Haldwani. Patients were randomly allocated to two groups of 50 patients each, Group 1 (Bupivacaine + Lignocaine) and Group 2 (Ropivacaine). In all cases peribulbar block was achieved by injecting $7-10 \mathrm{~mL}$ of the drug. Both groups were compared with respect to intraocular pressure change, onset of akinesia, postoperative pain and haemodynamic status after application of peribulbar block and surgeon's satisfaction at the end of surgery.

\section{RESULTS}

The demographic data of the patient and surgical duration were similar in both groups. Ropivacaine showed statistical significance in reduction of intraocular pressure and onset of akinesia 10 mins after the block. No significant difference was observed in haemodynamic status after the block. Both groups showed similarity in post-operative pain assessment and surgeon's satisfaction at the end of surgery.

\section{CONCLUSION}

It is inferred from our study that Ropivacaine is a good alternative for peribulbar anaesthesia compared to bupivacaine/lignocaine as it has a better safety margin, faster onset and lesser toxic effects than other comparable local anaesthetic agents.

\section{KEYWORDS}

Anaesthetics, Local; Anaesthetics, Conduction; Intraocular Pressure; Phacoemulsification.

HOW TO CITE THIS ARTICLE: Varshney R, Sharma V, Palaria U, et al. Ropivacaine versus bupivacaine-lignocaine mixture in peribulbar block- a comparative study. J. Evolution Med. Dent. Sci. 2017;6(48):3703-3706, DOI: 10.14260/Jemds/2017/799

\section{BACKGROUND}

Anaesthesia for ophthalmic surgery presents many unique challenges. It is essential to appreciate that ophthalmic drugs may significantly alter the effect to anaesthesia and that concomitantly anaesthetic drugs and manoeuvres may dramatically influence intraocular dynamics. Also, patients undergoing cataract surgery are usually represented by extremes of age and notable coexisting medical diseases (e.g. diabetes mellitus, coronary artery disease, essential hypertension, chronic lung disease).

As general anaesthesia can be precarious in the elderly population and not advisable in view of short procedure (10 - 15 mins), needle blocks are the most preferred for anaesthesia in ocular surgeries.

Financial or Other, Competing Interest: None.

Submission 10-05-2017, Peer Review 03-06-2017,

Acceptance 09-06-2017, Published 15-06-2017.

Corresponding Author:

Dr. Rahul Varshney,

Room No. 18, Senior Resident Hostel,

GMC Campus, Bareilly Road,

Haldwani-Nainital- 263139,

Uttarakhand, India

E-mail: drrahulvarshney@gmail.com

DOI: $10.14260 /$ jemds $/ 2017 / 799$

\section{(c) $(1) \ominus$}

Peribulbar injection of a local anaesthetic agent is an effective technique for cataract surgery and the most frequently used local anaesthetic agents for this procedure are lidocaine, bupivacaine or a combination.[1] These agents are known for their striking side-effects on cardiovascular and nervous systems. Newer agents like ropivacaine and carticaine with low systemic side effects have been introduced and found to be safe and effective for peribulbar anaesthesia in cataract surgery.

Ropivacaine is a monoamide local anaesthetic agent with a long-acting effect and a great margin of safety. The cardiac and central nervous system toxicity is less than bupivacaine.[2] The lower potential for systemic toxicity of ropivacaine compared with bupivacaine enables it to be used for surgical anaesthesia in higher concentration, which may facilitate diffusion of local anaesthetic molecules into peripheral nervous tissue, improving the onset of nerve blockade.[3]

\section{MATERIALS AND METHODS}

After proper Ethical clearance was obtained from Chairman and Members of Ethical Committee, Government Medical College, Haldwani, data was collected from patients scheduled to undergo elective cataract surgery by phacoemulsification under peribulbar block at Dr. Sushila 
Tiwari Memorial Hospital and Government Medical College, Haldwani. A prospective, randomised study was designed to collect data during the surgeries. Written informed consent to participate in the study was taken from all the patients, who were selected based on the American Society of Anesthesiologist's Physical Status classification system (ASA I-III). Patients younger than 45 years and older than 65, patients having any psychiatric illness (including significant anxiety), allergy to local anaesthetics and patients not giving consent were excluded from the study.

Following detailed pre-anaesthetic check-up, informed written consent was obtained from 100 consecutive patients fulfilling the required criteria. Patients were randomly and equally allocated into two groups, Group 1 (lignocaine + bupivacaine) and Group 2 (ropivacaine), consisting 50 patients each using computerised randomisation table kept centrally by a research staff nurse. The size of the study population was chosen on the basis of previous studies, taking difference in mean of degree of akinesia as primary variable. ${ }^{[4]}$ On the basis of previous studies, taking difference in mean of degree of akinesia as 2 with 5 as standard deviation of two groups, the minimum required sample size with $80 \%$ power of study and $5 \%$ level of significance is 98 patients. To reduce margin of error, total sample size taken is 100 (50 patients per group). ${ }^{[5]}$

Group 1 patients $(n=50)$ were given a 1:1 mixture of lidocaine $2 \%$ and bupivacaine $0.5 \%$ and Group 2 patients $(n=50)$ were given ropivacaine $0.75 \%$. An experienced ophthalmologist performed peribulbar block in all cases to eliminate bias due to multiple operator. A volume of 7 - 10 $\mathrm{mL}$ of local anaesthetic per patient was injected using a standard two-point, peribulbar injection technique with a 25 $\mathrm{mm}, 25-\mathrm{G}$ needle; $4-6 \mathrm{~mL}$ of anaesthetic was injected at the junction of the lateral third with the medial two-thirds of the inferior orbital edge, through the eyelid and the residual volume was injected in the upper internal edge of the eyeball through the upper eyelid. Orbital mechanical compression was applied to the closed eye for 15 minutes using a balanced weight between intermittent measurements. The pre- and post-block evaluation and measurements were performed by a second physician who was blinded to the local anaesthetic used.

Measurement of Intraocular Pressure (IOP) was performed using Schiotz tonometer at four time points: before block, $1 \mathrm{~min}, 5 \mathrm{mins}, 10 \mathrm{mins}$ and $15 \mathrm{mins}$ after giving block.

Quality of block was evaluated in terms of reduced ocular globe motility at $1 \mathrm{~min}, 5 \mathrm{mins}, 10 \mathrm{mins}$ and $15 \mathrm{mins}$ after injection using a three-point scoring system proposed by Nicoll and co-workers $0=$ Akinesia (ocular movement $<1 \mathrm{~mm}$ ), 1 = Reduced movement (ocular movement $>1 \mathrm{~mm}$ but $<4 \mathrm{~mm}$ ), $2=$ Normal movement (ocular movement $>4$ $\mathrm{mm}$ )), giving a maximal aggregate score of 8 for the four muscles.[6]

Haemodynamic status was assessed by recording pulse rate, oxygen saturation and Non-Invasive Blood Pressure (NIBP) before the block and at 1, 5, 10 and 15 minutes after the block.

Degree of postoperative pain was recorded by using a five-point verbal rating score at the first hour after the surgery $(0=$ no pain, $1=$ mild pain, $2=$ moderate pain, $3=$ severe pain, 4 = unbearable pain).
Surgical satisfaction was assessed by the surgeons as being poor, adequate or good.

\section{Statistical Analysis}

The data was entered in MS Excel spreadsheet and analysis was done using Statistical Package for Social Sciences (SPSS) version 24.0. Categorical variables were presented in number and percentage (\%) and continuous variables were presented as mean \pm SD and median. Statistical tests were applied as follows-

1. Quantitative variables were compared using unpaired ttest/Mann-Whitney Test (when the data sets were not normally distributed) between the two groups.

2. Qualitative variables were correlated using Chi-Square test/Fisher's exact test.

A $p$ value of $<0.05$ was considered statistically significant.

\section{RESULTS}

The study took place over a period of two months and proper record was maintained regarding demographic data and measured parameters at various steps. Patient's demographic characteristics and duration of surgery were similar in the two groups. There were no differences in the surgical procedures between two groups (Table 1).

\begin{tabular}{|c|c|c|}
\hline Parameters & $\begin{array}{c}\text { Group 1 } \\
\text { (Lignocaine + } \\
\text { Bupivacaine) }\end{array}$ & $\begin{array}{c}\text { Group 2 } \\
\text { (Ropivacaine) }\end{array}$ \\
\hline Age (Years) & $56.8 \pm 4.3$ & $57.2 \pm 5.1$ \\
\hline Gender (M/F) & $26 / 24$ & $28 / 22$ \\
\hline ASA Physical Status (I/II/III) & $20 / 25 / 05$ & $17 / 27 / 06$ \\
\hline Duration of Surgery (min) & $22.3 \pm 2.2$ & $21.4 \pm 3.4$ \\
\hline \multicolumn{2}{|c|}{$\begin{array}{c}\text { Table 1. Demographic Data, ASA Status } \\
\text { and Surgical Duration Comparison }\end{array}$}
\end{tabular}

Data are presented as mean or number of patients. There were no significant differences between groups. M: Male, F: Female; ASA: American Society of Anaesthesiologists.

The IOP data was comparable in both the groups before giving block. There was no statistical difference at $1 \mathrm{~min}$ and 5 mins after the block. Significant difference in intraocular pressure was observed between both groups at 10 and 15 mins (Table 2).

\begin{tabular}{|c|c|c|c|}
\hline $\begin{array}{c}\text { Intraocular } \\
\text { Pressure }\end{array}$ & $\begin{array}{c}\text { Group 1 } \\
\text { (Lignocaine + } \\
\text { Bupivacaine) }\end{array}$ & $\begin{array}{c}\text { Group 2 } \\
\text { (Ropivacaine) }\end{array}$ & P value \\
\hline Before & $14.67 \pm 2.07$ & $14.41 \pm 1.98$ & 0.5225 \\
\hline 1 min & $16.23 \pm 2.21$ & $15.7 \pm 2.17$ & 0.2292 \\
\hline 5 mins & $16.11 \pm 2.45$ & $15.3 \pm 2.52$ & 0.1064 \\
\hline 10 mins & $15.87 \pm 2.76$ & $14.7 \pm 2.50$ & $0.0286^{*}$ \\
\hline 15 mins & $13.90 \pm 3.12$ & $12.5 \pm 2.91$ & $0.0233^{*}$ \\
\hline \multicolumn{4}{|c|}{ Table 2. Intraocular Pressure } \\
\hline
\end{tabular}

Data are presented as mean \pm SD. *Statistically significant.

In our study, motor blockade onset was achieved early in ropivacaine group than the group with combination of Lignocaine and Bupivacaine, but was significant only at and after 10 minutes. (Table 3) During the early period of block, the akinesia score was comparable between both the groups (Figure 1). 


\begin{tabular}{|c|c|c|c|}
\hline Akinesia & $\begin{array}{c}\text { Group 1 } \\
\text { (Lignocaine + } \\
\text { Bupivacaine) }\end{array}$ & $\begin{array}{c}\text { Group 2 } \\
\text { (Ropivacaine) }\end{array}$ & P value \\
\hline Before Block & 8 & 8 & - \\
\hline $1 \mathrm{~min}$ & $5.3 \pm 1.94$ & $4.8 \pm 1.77$ & 0.1813 \\
\hline $5 \mathrm{mins}$ & $4.2 \pm 1.66$ & $3.7 \pm 1.57$ & 0.1250 \\
\hline $10 \mathrm{mins}$ & $2.3 \pm 1.23$ & $1.6 \pm 1.31$ & $0.0070^{*}$ \\
\hline $15 \mathrm{mins}$ & $0.8 \pm 0.45$ & $0.3 \pm 0.12$ & $0.0001^{*}$ \\
\hline \multicolumn{2}{|c|}{ Table 3. Degree of Akinesia Comparison between } \\
the Two Groups in the Four Intraocular Muscles \\
\hline
\end{tabular}

Data are presented as mean \pm SD. *Statistically significant.

No statistical significance was observed in haemodynamic status, i.e. pulse rate, oxygen saturation and non-invasive blood pressure between the two groups.

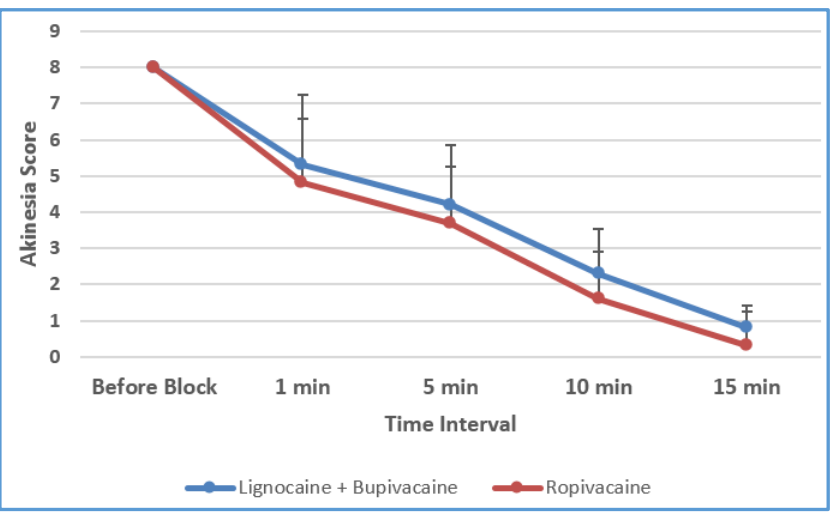

Figure 1. Mean Akinesia Score for Both the Groups at different Time Intervals

Both groups showed similarity in post-operative pain assessment and surgical satisfaction. Only 1 patient in Ropivacaine and 2 patients from Lignocaine and Bupivacaine group complained of moderate pain.

\section{DISCUSSION}

We compared the efficacy of $0.75 \%$ ropivacaine with $1: 1$ mixture of $0.5 \%$ bupivacaine and $2 \%$ lidocaine. The comparison focused on intraocular pressure dynamics, onset of action, quality of blockade and haemodynamic stability.

Bupivacaine alone might seem more appropriate as a control drug than the lidocaine-bupivacaine mixture; however, the lidocaine-bupivacaine mixture is currently used at our Institution for peribulbar block, combining lidocaine's onset time and the long postoperative pain relief of bupivacaine.[7-9]

Both groups can be considered similar with respect to demographic characteristics and basal levels of parameters evaluated before the block. There were no significant changes in the heart rate, blood pressure or oxygen saturation in any group suggesting that peribulbar blockade using plain $0.75 \%$ ropivacaine is a safe technique, as the traditional techniques of lignocaine/bupivacaine. Minor changes that occurred in blood pressure and heart rate in both groups did not interfere significantly with ocular changes.

Both our groups demonstrated similar latency and quality of blockade in the early 5 mins post application of block. With almost complete akinesia achieved by 15 mins of peribulbar block in both groups, the degree of akinesia achieved was faster with ropivacaine and the difference was statistically significant. It has been suggested that in peribulbar anaesthesia, the differences in the potency of the motor blockade between both anaesthetics could be concentrationdependent.[10] Comparison of different concentrations of ropivacaine in 68 patients showed that the concentration of $0.75 \%$ is preferable to $0.5 \%$ and $1.0 \%$, which produce respectively lower akinesia and prolonged anaesthetic recovery. ${ }^{[4]}$ In a study that compared peribulbar ropivacaine, racemic bupivacaine and levobupivacaine, all in concentrations of $0.75 \%$. No significant difference in quality of motor blockade was noted.[11] Equimolar concentrations of ropivacaine and bupivacaine in peribulbar anaesthesia seem to have the same anaesthetic potency.[12]

Peribulbar anaesthesia causes a temporary increase in the intraocular pressure due to the compressive effect of anaesthetic solution on the eye and increase in intraorbital pressure. However, after the onset of akinesia, due to relaxation of ocular musculature, a reduction in intraocular pressure is observed.[13]

Notable reduction in intraocular dynamics was observed between the two groups 10 mins after peribulbar block. Though, both the drugs $0.75 \%$ ropivacaine and $0.5 \%$ bupivacaine reduced intraocular pressure significantly from the baseline value, but ropivacaine decreased the IOP to a greater extent than bupivacaine. This finding is similar to reduction in IOP when used in peribulbar block.[10,13,14] In a study by Nociti JR, despite similar blockade with analgesia and akinesia $1 \%$ ropivacaine decreased the intraocular pressure immediately after its administration, unlike $0.75 \%$ bupivacaine which promoted an initial elevation in intraocular pressure followed by a reduction. The authors suggested that the difference could be due to the vasoconstrictive action of ropivacaine. Similar reduction in IOP was also seen in many studies evaluating ropivacaine in peribulbar block.[13]

The minor elevation in IOP with lignocaine/bupivacaine group, though statistically significant in comparison to ropivacaine was insignificant clinically and never did it reach abnormally high levels.

Our finding regarding onset of peribulbar block and postoperative pain is consistent with study done by Gioia et al who compared $0.75 \%$ ropivacaine with $1: 1$ mixture of $2 \%$ lignocaine and $0.5 \%$ bupivacaine for peribulbar anaesthesia in vitreoretinal surgery.[4]

\section{CONCLUSION}

Due to the similar characteristics in motor and sensitive blockade, intraocular dynamics and its lower systemic toxicity, ropivacaine represents an effective alternative to mixture of bupivacaine/lignocaine in peribulbar anaesthesia. Therefore, $0.75 \%$ ropivacaine alone is a suitable option for performing peribulbar block in cataract surgery.

\section{REFERENCES}

[1] Smith GB, Hamilton RC, Carr CA. Ophthalmic anaesthesia; a practical handbook. $2^{\text {nd }}$ edn. London: Arnold 1996:164-9. 
[2] Martini E, Cavallini GM, Campi L, et al. Lidocaine vs ropivacaine for topical anaesthesia in cataract surgery (1). J Cataract Refract Surg 2002;28(6):1018-22.

[3] Pescosolido N, Scarsella G, Tafani M, et al. Cataract surgery complications: an in vitro model of toxic effects of ropivacaine and lidocaine. Drugs $R$ D 2011;11(4):303-7.

[4] Gioia L, Fanelli G, Casati A, et al. A prospective, randomized, double blinded comparison of ropivacaine $0.5 \%, 0.75 \%$ and $1 \%$ ropivacaine for peribulbar block. J Clin Anesth 2004;16(3):184-8.

[5] Chow S, Shao J, Wang H. Sample size calculations in clinical research. $2^{\text {nd }}$ edn. Chapman \& Hall/CRC Biostatistics Series. 2008.

[6] Nicoll JM, Treuren B, Acharya PA, et al. Retrobulbar anesthesia: the role of hyaluronidase. Anesth Analg 1986;65(12):1324-8.

[7] Stead SW, Beatie DB, Keyes MA. Anesthesia for ophthalmic surgery. In: Longnecker DE, Tinker JH, Morgan GE. eds. Principles and practice of anesthesiology. St Louis: Mosby 1998:2181-99.

[8] Weiss JL, Deichman CB. A comparison of retrobulbar and periocular anesthesia for cataract surgery. Arch Ophthalmol 1989;107(1):96-8.
[9] Demediuk OM, Dhaliwal RS, Papwort DP, et al. A comparison of retrobulbar and periocular anesthesia for vitreoretinal surgical procedures. Arch Ophthalmol 1995;113(7):908-13.

[10] Huha T, Ala-Kokko TI, Salomaki T, et al. Clinical efficacy and pharmacokinetics of $1 \%$ ropivacaine and $0.75 \%$ bupivacaine in peribulbar anaesthesia for cataract surgery. Anaesthesia 1999;54(2):137-41.

[11] Magalhães E, Govêia CS, Oliveira KB. Bupivacaína racêmica, levobupivacaína e ropivacaína em anestesia loco regional para oftalmologia: um estudo comparativo. Rev Assoc Med Bras 2004;50(2):195-8.

[12] Govêia CS, Magalhães E. Ropivacaine in peribulbar anesthesia - vasoconstrictive properties. Rev Bras Anestesiol 2010;60(5):495-512.

[13] Nociti JR, Serzedo PS, Zuccolotto EB, et al. Intraocular pressure and ropivacaine in peribulbar block: a comparative study with bupivacaine. Acta Anaesthesiol Scand 2001;45(5):600-2.

[14] Perello A, George J, Skelton V, et al. A double-blind randomized comparison of ropivacaine $0.5 \%$, bupivacaine $0.375 \%$-lidocaine $1 \%$ and ropivacaine $0.5 \%$ - lidocaine $1 \%$ mixtures for cataract surgery. Anesthesia 2000;55(10):1003-7. 